\title{
VEBEX: Vegetation and surface energy balance experiment for the tropics
}

\author{
Sethu Raman ${ }^{1}$, Devdutta $S$ Niyogi ${ }^{1}$, A Prabhu $^{2}$, S Ameenullah $^{2}$, S T Nagaraj ${ }^{3}$, \\ UDAI KUMAR ${ }^{3}$ and S JAYANNA ${ }^{3}$ \\ ${ }^{1}$ State Climate Office of North Carolina, and Department of Marine, Earth, and Atmospheric Sciences, \\ North Carolina State University, Raleigh, NC, USA \\ ${ }^{2}$ Center for Atmospheric Sciences, Indian Institute of Science, Bangalore, India \\ ${ }^{3}$ University of Agricultural Sciences, Bangalore, India
}

Surface features such as soil moisture and vegetation have a profound impact on the surface energy balance and the atmospheric boundary layer. To quantify this effect for a tropical location, a detailed field experiment, VEBEX, was designed and successfully executed in a tropical site at Bangalore, India. VEBEX was a joint experiment between the North Carolina State University, Indian Institute of Science (IISc), and the University of Agricultural Science (UAS) at Bangalore, India. Continuous surface meteorological measurements were taken over an entire crop period (pre-sowing to post-harvest). During different stages of the plant growth, intensive observations of surface turbulence, and measurements of physiological and soil moisture measurements were also conducted. The results obtained provide an insight into the unusually strong variability for the tropics. Interpretation of the observations and an overview of the analysis procedure and future research initiatives are also presented.

\section{Introduction}

One of the pivotal components of present research efforts is to improve numerical model performance by accurately understanding and representing the effects of soil moisture and vegetation changes in the boundary layer. Consequently, various vegetation and soil moisture schemes are being used for soil vegetation atmosphere transfer (SVAT) studies. Some examples of such SVAT schemes for general circulation models (GCMs) are, Jarvis (1976); BATS (Dickinson et al 1986); SiB (Sellers et al 1986); SSiB (Xue et al 1991); Viterbo and Beljaars (1995); PLACE (Wetzel et al 1995); SiB2 (Sellers et al 1996). Examples for the planetary boundary layer (PBL) or mesoscale analysis include, Deardorff (1978); Noilhan and Planton (1989); Acs (1994); and Alapaty et al (1997a). Some of the recent studies are at the microscale, to evaluate the plant-to-plant response and leafscale interactions, using observational (Niyogi and Raman 1997; Katul et al 1997) as well as modeling approaches (cf. Baldocchi 1994; Nikolov et al 1995; Su et al 1996; Niyogi et al 1997a). The SVAT schemes, though developed from sound physics and understanding of the biosphere-atmosphere mechanisms, need to be simplified (and often tuned) through empirical equations, 'constants', and regionally representative features. For example, in Noilhan and Planton (1989), much of the physiological simplification and 'tuning' is done based on the empirical relations developed from HAPEX-MOBILHY observations (André et al 1986). Such a scheme could thus be a better representative of a mid-latitudinal geography and pasture-like landscape with relatively abundant moisture availability (consistent with HAPEX). Such empirical simplifications however, may not have an ubiquitous applicability, for they represent a somewhat limited (as against global) hydrological and landscape regimes. Thus, any biospheric scheme developed needs to be evaluated tested with global datasets. Unfortunately, such a global dataset is not available with the same information and high resolution, so as

Keywords. Planetary boundary layer; biosphere-atmosphere interaction; SVAT; tropics; field experiment. 
to allow a robust testing of the surface parameterizations and biospheric representations. To ascertain the confidence within such schemes or models, various micrometeorological point measurement validations need to be carried out regionally (cf. Sellers and Dorman 1987 for $\mathrm{SiB}$ ). Though such validations may have limitations, such as homogeneity: a feature never accounted in reality, one cannot deny their significance towards an advanced understanding of surface layer turbulence or SVAT mechanism. Hence, this has lead to application of micrometeorological analysis to various similiar atmospheric turbulence and SVAT related experiments related to atmospheric turbulence and SVAT studies such as FIFE (Sellers and Hall 1992), and HAPEX-MOBILHY (André et al 1986), and the recent land surface experiment in Anand, India (K G Vernekar, personal communication 1997).

VEBEX was designed to understand the significant energy balance features in the tropics through micrometeorological field measurements. This field program, as in the earlier other experiments, was designed to achieve several objectives. Some of the expectations from VEBEX included:

- validation of existing land surface and vegetation/ SVAT schemes,

- development of 'constants' or 'tuning' of the simplified models, statistical or empirical equations based on local (tropical) landscape and geography,

- development of a coupled physiological-hydrological-meteorological modeling framework,

- evaluate, and interpret the tropical hydrological cycles for diurnal, seasonal and inter-annual changes, with parallel measurements of soil moisture, temperature, plant-scale transpiration and soil evaporation,

- experimentally quantify the changes in the surface turbulence as a function of the surface features such as soil moisture and vegetation resistance and roughness (using spectral and energy balance approach) and

- increase the strength of the existing global dataset through information on climatic parameters on physiological processes such as stomatal behavior, evapotranspiration and photosynthetic and nutrient control.

The attainment of the above mentioned objectives for the tropics, is a useful step in PBL/SVAT modeling for the tropics. The tropics cover nearly $50 \%$ of the earth's surface and ecological features. The dynamics of the tropical atmospheric flows in tropics, is known to be different than in the midlatitude flows. Even the sustainability, and plant-to-plant response may be much more non-linear than one perceives for the midlatitudes (cf. Meinzer et al 1995; Hacker and Bertness 1995). Thus similarly, in terms of the biosphere-atmosphere interaction, our present knowledge is rudimentary and patchy. The harshly con- trasting regimes, induced by the dry and wet spells through the monsoon, are the key features of the tropical domain. Under these regimes, various significant surface changes (such as soil moisture change from wilting to saturation, and rapid plant and vegetation growth from earlier barren landscape) take place. Understanding of these regimes and their interactive effects cannot be developed from observations made in midlatitudes. Hence GCM and PBL studies in the tropics have always been assigned a high degree of uncertainty in terms of their predictions. Consequently, the genesis of VEBEX lies in the need to develop an understanding of some of the biosphere-atmosphere processes in tropics using in situ micrometeorological observations and field measurements.

\section{Experimental setup}

The observation setup for VEBEX included micrometeorological instrumentation, data acquisition, and physiological and soil surface related measurements. In collaboration with the University of Agricultural Science (UAS) at Bangalore $\left(12.59^{\circ} \mathrm{N}, 77.40^{\circ} \mathrm{E}\right)$, an experimental agricultural field of about $5.0 \times 10^{5} \mathrm{~m}^{2}$ was assigned for this study. Within this field, two adjacent plots were selected for the tower observations. One plot was maintained bare while the other had vegetation during the course of the study. The crop grown was Dolichous Biflorus (horse gram). Each of these plots had a $6 \mathrm{~m}$ tower. (Details of atmospheric instrumentation installed on the towers is given in table 1). Some of the motivating factors for keeping the two experimental plots contrasting (bare against vegetated) were: (a) the difference in the surface layer features could be due to different surface forcing alone (such as changes in vegetation cover, LAI, stomatal resistance and soil moisture change), (b) the need for developing an independent dataset for bare soil surface turbulence, and hydrology, (yet another feature not too well understood for the tropics), (c) to assist data quality control by using spectral and turbulence checks developed for bare surfaces (cf. Kaimal and Finnigan 1994) (d) to utilize advanced data analysis procedures using statistical techniques such as Factor Separation (Stein and Alpert 1993), or Fractional Factorial approach (Henderson-Sellers 1993; Niyogi 1996; Niyogi et al 1995, 1996, 1997b, c, d) or Response Surface techniques (Niyogi et al 1997c, d) applied successfully for land surface schemes. These techniques require a 'base state' data for analyzing the indirect and interactive effects and developing or testing statistical hypotheses (see Niyogi 1996 for details). Other aspects one could achieve with the combination of vegetated and bare plot are (a) estimating effective fluxes or area averaging of the fluxes (b) evaluate turbulence kinetic 
Table 1. Tower component applied in VEBEX observations.

\begin{tabular}{|c|c|c|}
\hline $\mathrm{Sr}$ & Component & Description \\
\hline 1. & Tower & $\begin{array}{l}6 \mathrm{~m} \text {. uniform triangular guyed to withstand } 180 \mathrm{~km} / \mathrm{hr} \text { wind with three levels } \\
\text { of retractable booms for instruments. }\end{array}$ \\
\hline 2. & Wind speed anemometers & $\begin{array}{l}\text { Operating range: } 0-10 \mathrm{~m} / \mathrm{s} \text {; Accuracy: } 1.5-2 \% \text { of full scale; Threshold: } 0.1 \mathrm{~m} / \mathrm{s} \text {; } \\
\text { Distance constant } 0.3 \mathrm{~m} \text {; Rotor: } 160 \mathrm{~mm} \text { dia; Cup: } 50 \mathrm{~mm} \text { dia; Output: Digital } \\
\text { pulse train. }\end{array}$ \\
\hline $2 b$. & Wind Translators & $\begin{array}{l}\text { Conversion accuracy: } 0.4 \% \text {; Output impedance: less than } 100 ; \text { Operating } \\
\text { temperature: }-10 \text { to } 60 \mathrm{C} \text {; Voltage }-5 \text { to } 5 \mathrm{~V} \text {; Operating voltage: }+/-12 \mathrm{~V} \text {; } \\
\text { Operating current }<0.4 \mathrm{~mA} \text {. }\end{array}$ \\
\hline 3. & Wind direction vane & $\begin{array}{l}\text { Operating range: } 0-360^{\circ} ; \text { Accuracy: }+/-3 \text {; Threshold: } 0.3 \mathrm{~m} / \mathrm{s} ; \text { Dist. Const: } \\
1 \mathrm{~m} ; \mathrm{O} / \mathrm{P}: \text { Analog } 10 \mathrm{mV} / \mathrm{deg} ; \text { Arm length: } 0.45 \mathrm{~m} .\end{array}$ \\
\hline 3b. & Wind direction translator & $\begin{array}{l}\text { Output impedence: }<100 \text {; Operating temperature: }-10 \text { to } 60 \mathrm{deg} \text {; Output } \\
0-5 \mathrm{~V} \text { for } 360 ; \text { On site calibration option. }\end{array}$ \\
\hline 4. & Air temperature sensor & Platinum RTD type; Operating range: -50 to $50 \mathrm{C}$; Accuracy $+/-0.05 \mathrm{C}$. \\
\hline $4 \mathrm{~b}$. & Air temperature translator & $\begin{array}{l}\text { Time constant: }<1 \mathrm{~s} ; \text { Conversion accuracy: } 0.4 \% \text {; Operating Temperature: } \\
-10-60 \mathrm{C} ; \text { Output voltage: }+/-5 \mathrm{~V} ; \text { Operating Voltage: }+/-12 \mathrm{~V} \text {; Operat- } \\
\text { ing Current: }<4 \mathrm{~mA} \text {. }\end{array}$ \\
\hline 4c. & Radiation shield & $\begin{array}{l}\text { Mechanically aspirated radiation shield of aluminium on smooth revolving } \\
\text { sealed bearings. }\end{array}$ \\
\hline 5. & Air humidity sensor & $\begin{array}{l}\text { Thin-film capacitance, Range: } 0-100 \% \text {; Accuracy: }+/-1 \% \text {; Response time: } \\
<10 \sec \text { for } 5 \text { to } 95 \% \text { change in } \mathrm{RH} \text {; output } 10 \mathrm{mV} / \% \mathrm{RH} \text {. }\end{array}$ \\
\hline $5 \mathrm{~b}$. & Air humidity translators & $\begin{array}{l}\text { Conversion accuracy: } 0.4 \% \text { Output impedance: }<100 \text {; Operating temperature: } \\
-10 \text { to } 60 \mathrm{C} \text {; Output: }+/-5 \mathrm{~V} ; \text { Other features same as air temperature } \\
\text { translator including on-field calibration option. }\end{array}$ \\
\hline 6. & Soil temperature & $\begin{array}{l}\text { RTD Pt-100 type, Operating range: }-10 \text { to } 60 \mathrm{C} \text {; Accuracy: }+/-0.1 \mathrm{C} \text {; } \\
\text { response time }<0.05 \text { sec. }\end{array}$ \\
\hline 7. & Fast temperature sensor & $\begin{array}{l}\text { Platinum type; Accuracy } 0.1 \mathrm{C} \text {, response time }<0.05 \mathrm{sec} \text {., Time constant: } \\
0.01 \mathrm{~s} \text {; Resistance range: } 100-200 \text {. }\end{array}$ \\
\hline 8. & Gill propeller anemometer $(\mathrm{u}, \mathrm{v}, \mathrm{w})$ & $\begin{array}{l}\text { Range }+/-10 \mathrm{~m} / \mathrm{s} \text { for } \mathrm{u}, \mathrm{v} \text { and }+/-5 \mathrm{~m} / \mathrm{s} \text { for } \mathrm{w} ; 10 \mathrm{~Hz} \text { sampling frequency, } \\
\text { IR emitter detector pair with chopper for each component using RM Young } \\
\text { Propellors. }\end{array}$ \\
\hline 9. & Constant temperature hot wire & $\begin{array}{l}\text { Pt wire, nonlinear signal output for a preset range. Built-in overheat ratio, } \\
\text { Range }+/-10 \mathrm{~m} / \mathrm{s} \text { for } \mathrm{u}, \mathrm{v}, \mathrm{w} ; 10 \mathrm{~Hz} \text { sampling frequency. }\end{array}$ \\
\hline 10. & Data handling & $\begin{array}{l}\text { Campbell Scientific Inc. data logger } 21 \mathrm{X} \text {. Data stored on tape recorder. } \\
\text { Different programs used for the acquisition: (a) } 10 \mathrm{~Hz} \text { at specified time, (b) } \\
1 \mathrm{~Hz} \text { round the clock. PCM telemetry package IBM compatibility } 32 \text { channel } \\
\text { collection and data visualization system. }\end{array}$ \\
\hline
\end{tabular}

energy dissipation with step change in surface features. Such features, closely representing the problems of sub-grid scale heterogeneity and turbulence energy balance, could be studied through the detailed turbulence and physiological/hydrological observations as described in the following section.

\section{Observations}

After the tower was erected in 1994, the site scientists have been recording micrometeorological profile data and utilizing the tower for developing and testing better data acquisition and data collection procedures. From July 1995, the researchers involved were ready both in terms of requisite infrastructure and technical support, and the field campaign was resumed. Accordingly from August 14, 1995, five Intensive Observation Periods (IOPs) were conducted. The last IOP ended in January 1996. Table 2, lists the IOPs and various measurements made during this period. For this maiden attempt, emphasis was on collecting every possible information that would be required at least for satisfactorily validating existing vegetation and soil moisture parameterizations.

Some principal features of the measurements done during VEBEX include:

- Profiles of wind speed, temperature, humidity at three levels. These data $(1 \mathrm{~Hz}$ frequency, averaged 
Table 2. Observations during VEBEX (August 95-January 96). Crop Grown: Dolichos Biflorus (Horse Gram).

\begin{tabular}{lll}
\hline Day & \multicolumn{1}{c}{ Period } & \multicolumn{1}{c}{ Measurements } \\
\hline 182 & July 1st 1995 (TEST) & Slow data (SD) started WS (6), WD (2), RH (4) T (4). \\
$226-232$ & $\begin{array}{l}\text { August 14th-20th, '95 } \\
\text { Bare plots (IOP1) }\end{array}$ & SD, RDN, TST (IR, 1-3), GSM (3), CC, PPTN, EVP. \\
$237-8$ & August 25th-26th (IOP1A) & $\begin{array}{l}\text { Fast (Eddy Covariance) Data (FD) (u, v, w, T, q), in addn. to above } \\
\text { mentioned measurements. }\end{array}$ \\
257 & September 14th & Dolichos Biflorus Sowing; Installed SM, ST probes. \\
$259-64$ & September 16th-18th (IOP2) & SD, FD, RDN, TST (IR, 1-3), ST (3), SM (3) GSM (3), CC, PPTN, \\
& Sprouting & EVPs. \\
$286-87$ & October 13th-14th (IOP3) & LAI (5), VEG, PM, measured in addn. (Green up). \\
$293-98$ & October 20th-25th (IOP3A) & LAI (5), VEG, PM, measured in addn. (Green up). \\
$325-29$ & November 21st-25th (IOP4) & LAI (5), VEG, PM, Psych. N, Rs, in addn. (Full green). \\
$340-45$ & December 6th-11th (IOP4B) & LAI (5), VEG, PM, Psych. N, Rs, in addn. (Full green). \\
$359-61$ & December 25th-27th (IOP5) & LAI (5), VEG, PM, Psych. N, Rs, in addn. (Green down). \\
$362-2$ & December 28th-January 2nd (IOP5B) & VEG, LAI (5), PM, Psych, N, Rs, in addn HW installed. \\
3 & January 3rd Harvest & Same as above without N, Rs, LAI direct measurements. \\
$4-7$ & January 4th-7th & Same as above, Measurements end. \\
\hline
\end{tabular}

Note: RDN (Incoming, outgoing Net Radn); TST (Thermometer soil temp); IR (Infra Red thermometer); GSM (Gravimetric Soil Moisture); CC (Cloud Cover); PPTN (Precipitation and Dew); EVP (Pan Evaporation); Psych (Psychrometer RH check); N (Leaf N measurement); Rs (Stomatal Resistance); PM (Plant measurements: root-shoot measurements, weights); HW (Hot Wire anemometer). Additionally $\mathrm{OZ}$ and $12 \mathrm{Z}$ radiosonde profiles were also obtained.

over 3 minutes) was nearly continuous for the entire experiment (July 1995 to January 1996). Additional instantaneous psychrometer data were collected for keeping a check on the humidity measurements.

- $10 \mathrm{~Hz}$ sampling of wind components, temperature, and humidity during the IOPs. This sampling time for the turbulence measurements was for 30 minutes and the measurements were generally made at $0600,0900,1200,1500,1800,2100$, and $2400 \mathrm{~h}$ LT. During some special observations (such as the partial solar eclipse of October 24th 1995, or the crop harvesting, near continuous fast data acquisition was done). The wind components were measured by using a Gill propeller type anemometer, and in the later stage supplemented with constant temperature hot-wire measurements.

- Soil temperature was recorded continuously in the vegetated plot every three minutes at three depths $(0.08,0.16$, and $0.32 \mathrm{~m}$ below the surface). In the bare plot, manual observations were also recorded taken from pre-existing thermometers embedded in the soil at the three depths. Additionally, during the IOPs, leaf temperature and surface skin temperature was measured using a hand-held infra-red (IR) thermometer. Net radiation (both incoming and outgoing) was also continuously measured at the two towers using net radiometers.
- Soil moisture was estimated at three depths in both the plots. This was done for at least two locations in each plot using gravimetric method during the IOPs. The gravimetric samples, had to be limited to the depth of about $0.5 \mathrm{~m}$ below the surface. This was done during the IOPs. Additionally, continuous soil moisture measurements (hourly) were made using gypsum blocks. The gypsum blocks were embedded at three depths $(0.1,0.3$ and $0.6 \mathrm{~m})$ in the vegetated plot, and at $0.6 \mathrm{~m}$ depth in the bare plot.

- Physiological parameters measured during VEBEX include leaf area index (LAI), fractional vegetal cover, leaf-shoot-root dimensions and weight, canopy nutrient status based on leaf nitrogen and phosphorus content, stomatal resistance, evapotranspiration and assimilation rates based on porometeric as well as nutrient empirical estimates (Schulze et al 1994; Niyogi et al 1997a), micrographic stomatal aperture estimates (S S Joshi, personal communication, 1995), and foliage and crop surface temperatures. These measurements were instantaneous and replicated with at least three sets of measurements (see Niyogi et al 1997a).

Additional data collected on a routine basis included: Pan evaporation from the bare ground from a preexisting facility, precipitation and estimation of height above ground level for dew formation measurements, and estimates of cloud cover. Soil characterization was 
also performed with information on particle size distribution, water retention characteristics, infiltration rates, Keen-Raczkowski measurements for soil expansion, pore spaces, water holding capacities, and chemical properties with conductivity. Thus, a comprehensive observational database was generated during VEBEX.

\section{Typical results and ongoing analysis}

Collecting the data and recording measurements, is just one part of the experiment. This data collection, needs a follow-up in terms of data analysis, quality control and validation, and archival. Thus presently, the VEBEX researchers are still in the process of collecting some missing background information such as the regional landscape, precipitation pattern which will be useful in the overall understanding of the complex tropical SVAT mechanism. However, analysis of the data for information on fluxes, spectral or turbulence characteristics has resumed. In particular, the data collected over the seven months, and during the five IOPs will have to be processed such that we have reliable data on surface fluxes and physiological features.

Figures 1-7 present some of the typical features obtained during VEBEX. Figure 1 shows the variation of fractional vegetal cover (VEG) and the leaf area index (LAI) over the experimental plot for 117 crop days. LAI was estimated from five replicates using destructive sampling procedure in the Plant Physiology Lab at the UAS. The fractional vegetal cover was estimated using in situ measurements by scaling the length and number of plants grown (and their coverage area) in a $1 \mathrm{~m}^{2}$ zone. The experimental period was divided into five IOPs based on the crop growth stage as shown in intensive observational periods indicated in figure 1 (solid horizontal bars). Before sowing, the LAI and VEG values were assigned to be zero (bare surface). After sowing (indicated by S along the $\mathrm{X}$-axis), the change of LAI was rather sluggish for the open canopy but the fractional vegetal cover changed rapidly. The maximum LAI obtained (figure 1) for the study period is relatively small as expected for the open canopy. An interesting subsurface hydrological and temperature variability as a function of the crop stage could be seen from the measurements. Figure 2 shows the typical soil moisture variation observed in the vegetated field during IOP IV (maximum green phase) for a period of 8 IOP days. Some features stand out distinctly. First is the strong diurnal variability. The observations were made at three depths of $10 \mathrm{~cm}, 30 \mathrm{~cm}$ and $60 \mathrm{~cm}$. Diurnal variations could even be seen up to a depth of $0.6 \mathrm{~m}$ for this tropical site. Such strong diurnal forcing on the soil moisture. were not observed for the midlatitude sites of FIFE and LAPEX. A second feature

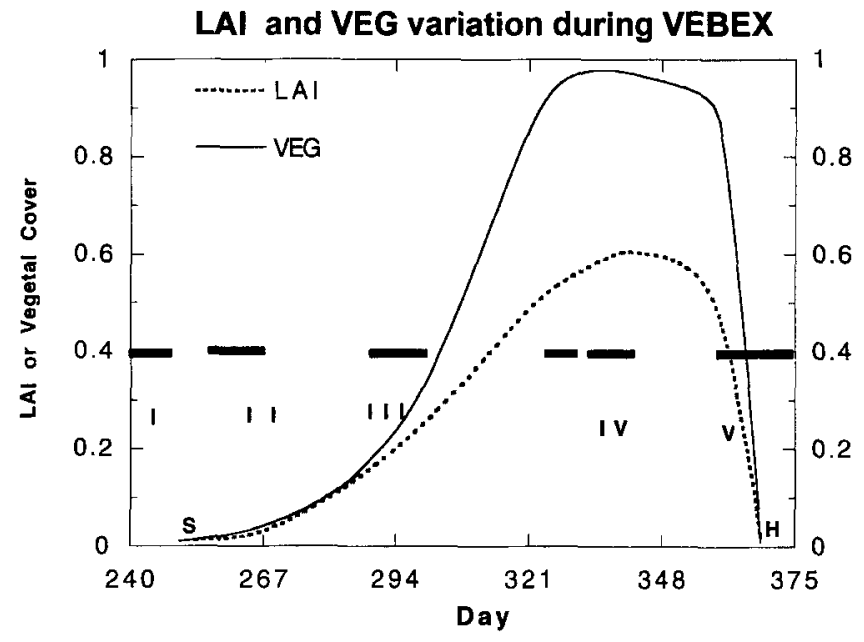

Figure 1. Estimated Leaf Area Index (LAI) and fractional vegetal cover (VEG) during VEBEX. The $x$-axis is the Julian day and ' $\mathrm{S}$ ' and ' $\mathrm{H}$ ' indicate sowing and harvesting respectively. The bold horizontal bars indicate different IOPs (see text).

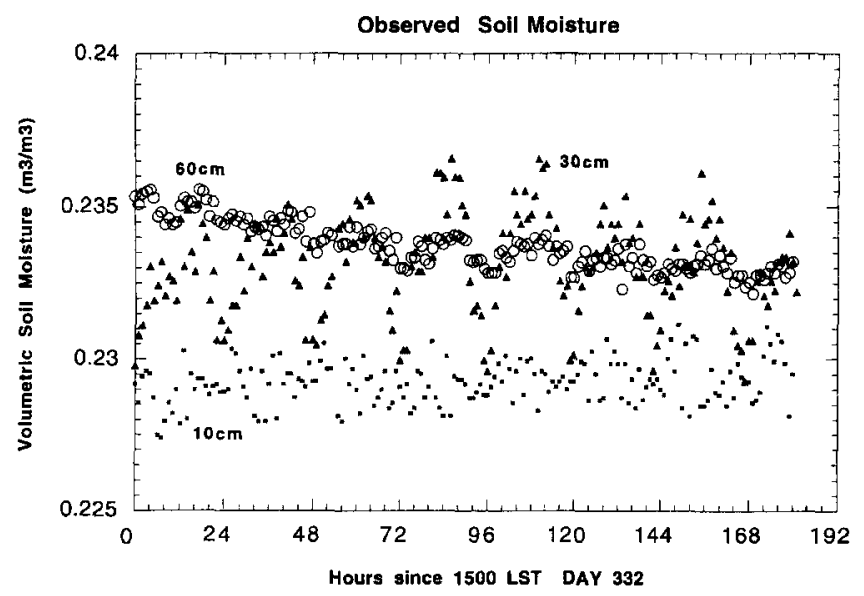

Figure 2. Typical observations of volumetric soil moisture variation over a period of eight days during VEBEX. The open circles represent deep soil moisture at $0.6 \mathrm{~m}$, triangles at $0.3 \mathrm{~m}$, and the closed squares represent soil moisture values for the top soil surface $(0.1 \mathrm{~m})$. Significant diurnal periodicity was seen for the tropical site along with a change in the vertical soil moisture gradient over the eight day period. These data were obtained continuously using gypsum soil moisture blocks and checked every twelve hours by the gravimetric method.

is the apparent vertical diffusion between the different soil layers (cf. Ek and Cuenca 1994). That is, the $0.6 \mathrm{~m}$ soil moisture shows a negative trend over the IOP and the upper soils (at $0.3 \mathrm{~m}$ and $0.1 \mathrm{~m}$ ) correspondingly exhibit an increased amplitude in the diurnal variability and a slightly positive trend. The root-zone for the experimental crop was estimated to be around 0.3 to $0.4 \mathrm{~m}$ from destructive measurements during this IOP. Such strong diurnal forcings on the soil moisture were not observed for the midlatitude sites of FIFE and HAPEX. Thus the evapotranspirative demand could provide an upward flux for the deeper soil moisture resulting in the depletion in the below-root layer 


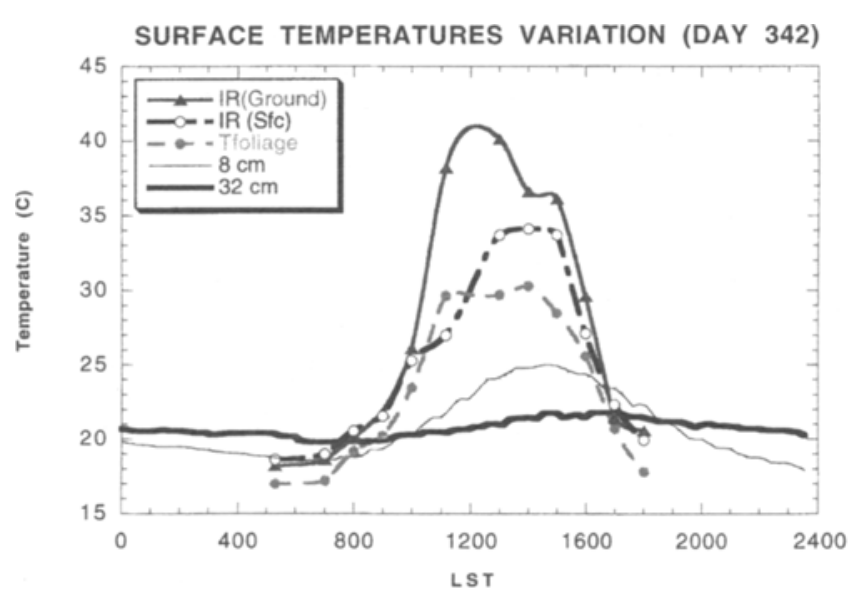

Figure 3. Observed surface temperatures over the vegetated field for $0.32 \mathrm{~m}$ and $0.08 \mathrm{~m}$ below surface, along with the foliage (leaf), bare ground, and the surface (combination of patchy vegetation and bare ground). Strong diurnal variability and a large difference in the temperatures as a function of the surface were obtained which have implications for remote sensing and effective parameter representation in the tropical domain.

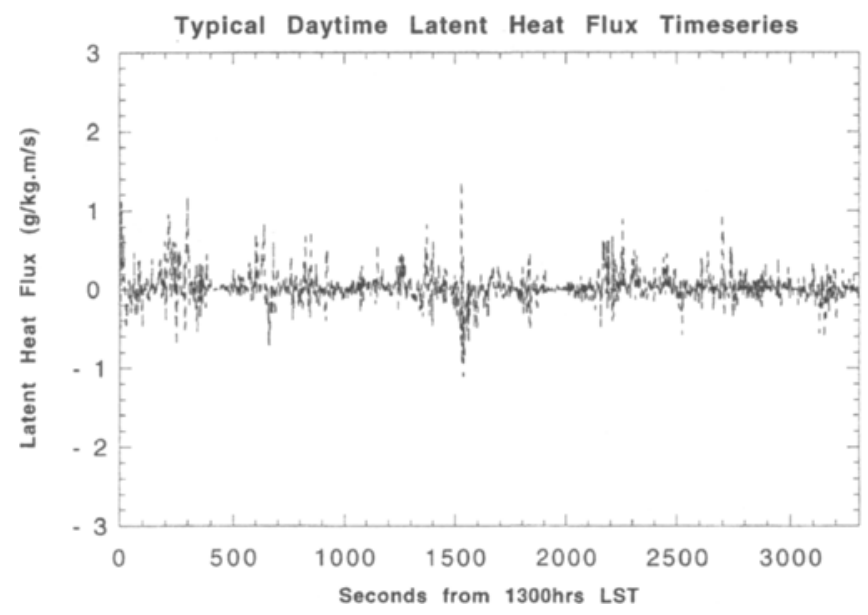

Figure 4. Typical daytime vertical velocity (w)-specific humidity $(q)$ instantaneous covariances. The individual ' $w$ ' and ' $q$ ' time-series were detrended, 'cleaned' for spurious peaks, and then plotted.

and an increase in the above root-zone. These results suggest a strong radiative as well as physiological control over the local hydrology in the tropics. This has important implications for assigning higher uncertainty to results from simple slab models which do not have detailed soil hydrology and vertical diffusion (see Alapaty et al 1997b; Niyogi et al 1997c). Figure 3 shows a typical surface and subsurface temperature data obtained during VEBEX IOP IV (day 342). The subsurface observations are from soilembedded sensors. Hourly temperature measurements of bare soil, foliage temperature, and surface (combined foliage and bare ground) at multiple locations were obtained using a hand held IR thermometer. As expected, the deep soil temperature $(0.32 \mathrm{~m}$ below surface) shows a weak amplitude of diurnal variation

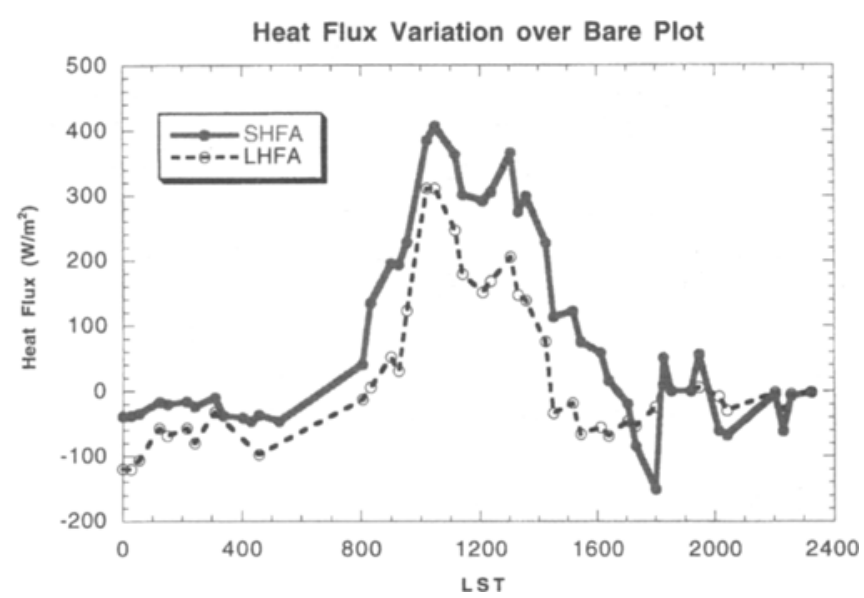

Figure 5. Typical time-history of surface heat flux variation over the bare experimental plot. The bold line represents sensible heat flux (SHFA) and the dashed, latent heat flux (LHFA). The sensible heat flux was higher than the latent due to the bare conditions and low evapotranspiration. The relatively high latent heat flux values was due to high soil moisture availability over the study domain.

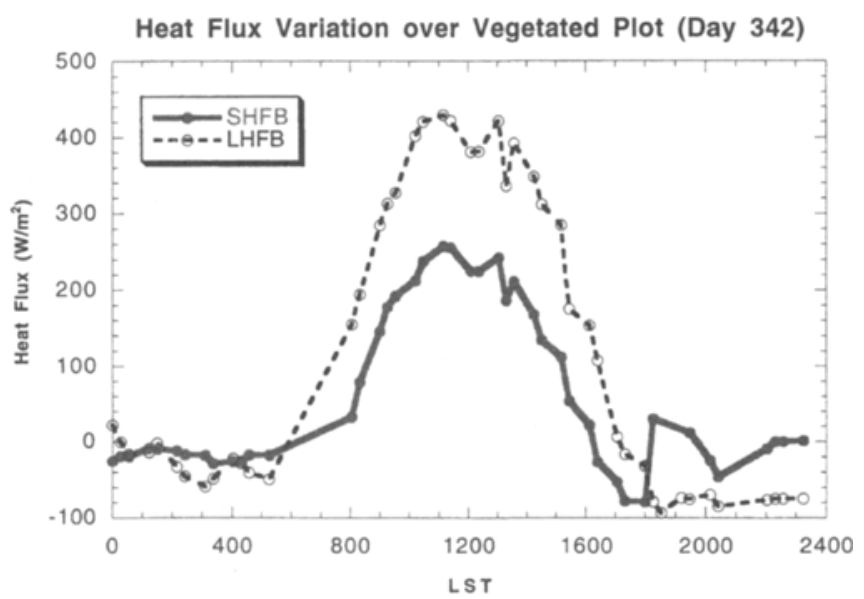

Figure 6. Typical time-history of surface heat flux variation over the vegetated plot. The bold line represents sensible heat flux (SHFB) and the dashed, latent heat flux (LHFB). Similar to bare plot (figure 5), significant diurnal variability was also seen for the vegetated plot. With availability of vegetation and soil moisture, the evapotranspirative (latent heat) flux was higher than the sensible.

and this amplitude increases as one reaches the surface, with a maximum for the top soil surface. An important feature of the observation is the large difference between the bare soil, foliage and the surface (combination of the patchy crop and bare soil). For a convective period around noon, the surface temperature (as estimated in the remote sense radiances) was found to be typically $5 \mathrm{~K}$ higher than the freely transpiring leaf or foliage temperature and about $5 \mathrm{~K}$ lower than the bare ground. It is expected that the range of such surface temperature extremes (fully vegetated to entirely bare ground) will have a seasonal component with cloudiness and soil moisture availability as well as a regional component with the 
land use and the vegetation characteristics (different photosynthetic pathways, open against closed canopy, and emissivity) and needs to be studied further apropos quantifying the tropical scenario. The strong vertical temperature gradients also indicate high surface energy fluxes in the experimental period. The measurements of surface turbulent energy fluxes were estimated made over the bare and vegetated field using eddy-correlation technique. On-site video-imagery and near-real time PCM telemetry setup developed at the Indian Institute of Science was utilized to obtain time-histories and aid quality control of the data procured. Further detrending, filtering, and statistical checks were also performed using standard algorithms (see Kaimal and Finnigan 1994). Figure 4 shows a typical detrended, convective moisture covariance time history over the vegetated plot. The covariance data were averaged to obtain energy fluxes in the surface layer as described in Stull (1986), and latent heat fluxes were estimated from such measurements. Figures 5 and 6 show the sensible and latent heat fluxes over the bare and vegetated fields respectively. As expected, the latent heat fluxes were larger and sensible heat fluxes smaller over the vegetated plot as compared to the bare plot due to surface evapotranspirative cooling. The values obtained are relatively higher than most midlatitudinal sites (cf. André et al 1986) but are consistent with the observations reported for such tropical locations in the literature (cf. Raman et al 1990). Future efforts will address the issue of effective flux representation (treating the vegetation and bare plot as one 'grid'). It will be interesting to investigate if the Bowen ratio would have a strong diurnal variability for this scenario. Also, it should be cautioned that the response period of the Gill Anemometer could make the estimates presented here slightly biased and would have to be compared with the flux estimates from other independent flux measurements such as through hot wire anemometer employed in the later part of the study. Both the results provide a fair estimate of the nature of diurnal variability one could estimate for the tropics as a function of surface forcing. Additionally, due to the changes in soil moisture, significant variation was obtained in the values of the surface albedo on diurnal (and seasonal) scales. Figure 7 shows the typical albedo changes over the bare and vegetated plots (for day 342) on 8th December 1995. Note that the vegetated field has a nearly constant albedo around 0.21 while the bare field albedo changed from 0.2 to 0.3 over the six hour period considered. The bare ground albedo shows a larger variation which can be principally attributed to the decrease because of the variation in the soil moisture over the bare plot during this period (cf. Idso et al 1975).

Thus, various interesting results were obtained for the bare against vegetated surface. These preliminary

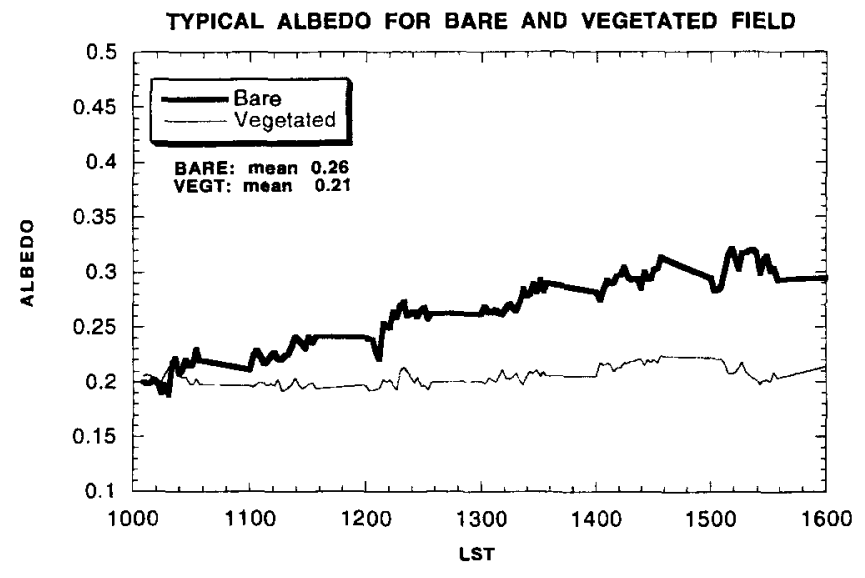

Figure 7. Typical albedo variation for the bare and vegetated fields. The vegetated field albedo (thin line) was approximately constant while the bare ground albedo (bold line) showed nonstationarity which could be attributable to the soil moisture changes.

results also show a consistency of the comprehensive dataset. Additionally, the phase and amplitude of the changes over the two surfaces provide an insight in the non-linearity of the area averaging for the fluxes as would be required for various remote sensing and weather forecast algorithms under contrasting vegetation regimes.

The information generated from VEBEX, will be utilized for satisfying our pre-mentioned objectives and also explore the possibility of developing better parameterizations. Some of the schemes that are on the agenda for verification include: mesoscale-related schemes such as Deardorff (1978); Noilhan and Planton (1989), as well as photosynthesis-based detailed physiological schemes such as LEAFC3 (Nikolov et al 1995), and the GCM-based schemes BATS, SiB, SSiB, and others. As for the Noilhan and Planton and Deardorff schemes, they are already incorporated within the North Carolina State University (NCSU) model (Huang and Raman 1991; Alapaty et al 1997a) and LEAFC3 is presently being linked. Additionally, a higher order closure model with implicit heterogeneity (Rao et al 1974), along with a non-hydrostatic regional model with the Noilhan and Planton scheme (ARPS 1995) will also be used for simulating the turbulence features over the study region. Our objective is to thus provide a hierarchy of evapotranspiration schemes such as, Bowen ratio technique, Penman-Monteith technique, Priestley-Taylor method, Noilhan and Planton (1989) with implicit soil and vegetation fluxes, Deardorff (1978) or Bosilovich and Sun (1995) with explicit soil and vegetation fluxes, and Ball-Berry model (Ball 1988; Niyogi and Raman 1997) a physiological photosynthesis-evapotranspiration approach, for their predictability will be evaluated. Such evaluations are planned for different hydrological regimes (diurnal, weekly, and seasonal scales). Our starting hypothesis 
is that for non-stationary soil moisture conditions (dry to wet or wet to dry) and for relatively long periods (few days), advanced schemes might perform better for tropics where the landscape undergoes a dramatic change. Conversely, for near-stationary hydrological and physiological conditions, the different approaches would have a similar outcome. Other significant results from VEBEX database include a development of a nutrient-based stomatal resistance mapping technique (Niyogi et al 1997b) following an approach adopted by Schulze et al (1994). Stomatal resistance controls the regional evapotranspirative demand and thus has tremendous implications for hydrological and agricultural as well as medium-range weather forecasting. Recent studies (Alapaty et al 1997b; Niyogi et al 1997c) have attributed a high range of uncertainty to this parameter in error propagation. Hence, it will be of interest to apply first-order approximation techniques developed during VEBEX for a regional thematic mapping framework in the future. Another problem that will be of interest to the VEBEX researchers is the area averaging of fluxes, and turbulence dissipation due to step-change of surface features, and will be discussed in future.

\section{Conclusion}

A focused field experiment with emphasis on surface energy budget and related plant physiology was successfully executed at a tropical site in Bangalore, India. Results indicate interesting non-linearities in the interaction between surface features and the resulting turbulent energy fluxes. The resulting impact of the surface characteristics is hypothesized to be a dominant forcing since the synoptic forcing is weak in the tropics. Also, results obtained from VEBEX revealed, that the absolute magnitude of the surface forcings had a large amplitude and significant diurnal variability. This further increases the significance of recognizing the role of surface features in the tropical scenario. Thus, modeling efforts will require a high degree of sophistication to simulate the non-linear interaction evident in the tropical scenario such as that over the Indian peninsula. Particularly, evapotranspirative parameters such as stomatal resistance, vertical diffusion of sub-surface soil moisture, and surface temperature estimation will be a challenging task in the medium range forecast and planetary boundary layer models. Future efforts from the VEBEX community will address these and related aspects.

\section{Acknowledgements}

We would like to gratefully acknowledge the support provided by all the participating institutes particu- larly the North Carolina State University, as also the Center for Atmospheric Sciences and Department of Aerospace Engineering of the Indian Institute of Science for computational and instrumental facilities and hospitality, and the University of Agricultural Sciences for the instrumental and man power support. Thanks are also due to the India Meteorological Department for providing supporting upper air information for Bangalore during the IOPs. The experiment benefited tremendously because of the interest and discussions with a large number of scientists notably, Prof. Roddam Narasimha, IISc, Prof. S Pal Arya, NCSU, Prof. Sulochana Gadgil, IISc, Dr. G S Bhat, IISc, Prof. U C Mohanty, IIT Delhi, Dr. K G Vernekar, IITM Pune, Prof. S S Joshi, UAS, and Dr. Dennis Baldocchi, ORNL, ATDD/ NOAA. Financial support for the experiment was provided through the U.S. National Science Foundation's Division of International Programs, Government of India's Department of Science and Technology, and the School of Physical and Mathematical Sciences at North Carolina State University.

\section{References}

ARPS 1995 Advanced Regional Prediction System, version 4.0; Users Manual. Available from Center from Analysis and Prediction of Severe Storms, University of Okalohama, Norman

Acs F 1994 A coupled soil-vegetation scheme: description, parameters, validation and sensitivity studies; J. Appl. Meteorol. 33 268-284

Alapaty K, Pleim J, Raman S, Niyogi D and Byun D 1997a Simulation of atmospheric boundary layer processes using local and nonlocal-closure schemes; J. Appl. Meteorol. 36 214-233

Alapaty K, Raman S and Niyogi D 1997b Uncertainty in specification of surface characteristics: A study of prediction errors in the boundary layer; Bound.-Layer Meteorol. 82 $473-500$

André J, Goutorbe B and Perrier A 1986 HAPEX-MOBILHY: A hydrological atmospheric experiment for the study of water budget and evaporation flux at the climatic scale; Bull. Amer. Meteorol. Soc. 67 138-144

Baldocchi D D 1994 A comparative study of mass and energy exchange over a closed C3 (Wheat) and an open C4 (Corn) canopy: The partitioning of available energy into latent and sensible heat exchange; Agricult. and Forest Meteorol. 67 $191-220$

Ball J T 1988 An analysis of stomatal conductance; Ph.D. thesis, Stanford Univ. p 89

Bosiolovich M and Sun J 1995 Formulation and verification of a land surface parameterization for atmospheric numerical models; Bound.-Layer. Meteorol. 73 321-341

Deardorff J 1978 Efficient prediction of ground surface temperature and moisture with inclusion of a layer of vegetation; J. Geophys. Res. 20 1889-1903

Dickinson R, Henderson-Sellers A, Kennedy $P$ and Wilson M 1986 Biosphere-atmosphere transfer scheme (BATS) for the NCAR community climate model; NCAR/TN-275 + STR

Ek M and Cuenca R 1994 Variation in soil parameters: Implications for modeling surface fluxes and atmospheric boundary layer development; Bound.-Layer Meteorol. 70 369-383 
Hacker S D and Bertness M 1995 Morphological and physiological consequences of a positive plant interaction; Ecology 76 2165-2175

Henderson-Sellers A 1993 A factorial assessment of the sensitivity of the BATS land-surface parameterization scheme; J. Climate 6 227-246

Huang C Y and Raman S 1991 Numerical simulation of January 28 cold air outbreak during GALE, Part I: The model and sensitivity tests of turbulence closure; Bound.Layer. Meteorol. 55 381-407

Idso S, Jackson R, Kimball B and Nakayama F 1975 The dependence of bare soil albedo on soil water content; J. Appl. Meteorol. 14 109-113

Jarvis P 1976 The interpretation of variations of leaf water potential and stomatal conductance found in the canopies in the field; Phil. Trans. R. Soc. London B273 593-610

Kaimal J and Finnigan J 1994 Atmospheric Boundary Layer flows: their structure and measurement; Oxford University Press

Katul G, Geron C, Hsieh C, Vidakovic B and Guenther A 1997 Active Turbulence and Scalar Transport near the ForestAtmosphere Interface; J. Appl. Meteorol. (submitted)

Meinzer F C, Goldstein G, Jackson P, Holbrook N M, Gutierrez M V and Cavelier J 1995 Environmental and physiological regulation of transpiration in tropical forest gap species: the influence of boundary layer and hydraulic properties; Oecologia $101514-522$

Nikolov N, Massman W and Schoettle A 1995 Coupling biochemical and biophysical processes at the leaf level: an equilibrium photosynthesis model for leaves of $\mathrm{C}_{3}$ plants; Ecol. Mod. 80 203-235

Niyogi D S 1996 Dynamic interactions in the soil-vegetationatmosphere transfer processes', M.S. thesis, North Carolina State University, $250 \mathrm{pp}$. [Available from Department of Marine, Earth, and Atmospheric Sciences, N C State University, Raleigh, NC 27695-8208]

Niyogi D S, Raman S and Alapaty K 1995 Interaction between vegetation and atmosphere in the planetary boundary layer; 22nd Nat. Conf. on Fluid Mech. and Fluid Power, 13th-15th Dec, Indian Inst, of Techn., Madras, India

Niyogi D S, Raman S and Alapaty K 1996 Towards a dynamic parameterization of vegetation in PBL models; 12th conference on Biometeorology and Aerobiology, 27th Jan2nd Feb, Atlanta; Amer. Meteorol. Soc. Boston

Niyogi D S and Raman S 1997 Comparison of stomatal resistance simulated by four different schemes using FIFE observations; J. Appl. Meteorol. 36 903-917

Niyogi D S, Raman S, Prabhu A, Kumar U and Joshi S 1997a Direct estimation of stomatal resistance for meteorological applications; Geophys. Res. Lett. 24 1771-1774

Niyogi D S, Raman S, Alapaty K and Han J 1997b A dynamic statistical experiment for atmospheric interactions; Environ. Model. Assess. (A) 2 307-322
Niyogi D S, Alapaty K and Raman S 1997c Uncertainty in the specification of surface characteristics: Heirarchy of Interaction-Explicit statistical analysis; Bound.-Layer Meteorol. (in press)

Niyogi D S, Raman S and Alapaty K 1997d Comparison of stomatal resistance simulated by four different schemes using FIFE observations, Part 2 Hierarchy of interaction explicit statistical analysis; $J$. Appl. Meteorol. (in press)

Noilhan J and Planton S 1989 A simple parameterization of land surface processes for meteorological models; Mon. Weather Rev. 117 536-549

Raman S, Templeman B, Templeman S, Murthy A B, Singh M P, Agarwaal P, Nigam S, Prabhu A and Ameenullah S 1990 Observation of mean boundary layer structure and turbulence during pre-monsoon and monsoon periods in India; Atmos. Environ. 24A 723-734

Rao K S, Wyngaard J and Cote O 1974 Local advection of momentum, heat, and moisture in micrometeorology; Bound.-Layer Meteorol. 7 331-348

Schulze E, Kelliher F, Korne C and Lloyd J 1994 Relationships among maximum stomatal conductance, ecosystem surface conductance, carbon assimilation rate, and plant nitrogen nutrition: A global ecology scaling exercise; Annu. Rev. Ecol. Syst. 25 629-660

Sellers P and Hall F 1992 FIFE in 1992: Results, scientific gains, and future research directions; J. Geophys. Res. 97 D17, 19091-19109

Sellers P and Dorman J 1987 Testing the Simple Biosphere Model (SiB) with point micrometeorological and biophysical data; J. Clim. Appl. Meteorol. 26 622-651

Sellers P, Mintz Y, Sud Y and Dalcher A 1986 The design of a simple biosphere model ( $\mathrm{SiB})$ for use within general circulation models; J. Atmos. Sci. 45 505-531

Sellers P, Randall D, Collatz J, Berry J, Field C, Dazlich D, Zhang C, Collelo G and Bounous A 1.996 A revised land surface parameterization (SiB2) for atmospheric GCMs: Model formulation; J. Climate 9 676-705

Stein U and Alpert P 1993 Factor separation in numerical simulations; J. Atmos. Sci. 50 2107-2115

Stull R 1986 An Introduction to Boundary Layer Meteorology; Kluwer Academic Publication

Su H B, Paw U K T and Shaw R 1996 Development of a coupled leaf and canopy model for the simulation of plantatmosphere interaction; J. Appl. Meteorol. 35 734-748

Viterbo P and Beljaars A 1995 An improved land surface parameterization scheme in the ECMWF model and its validation; $J$. Climate 8 2716-2748

Wetzel P and Boone A 1995 A parameterization for LandAtmosphere-Cloud Exchange (PLACE): Documentation and testing of a detailed process model of the partly cloudy boundary layer over heterogeneous land; J. Climate 8 1810-1835

Xue Y, Sellers P, Kinter J and Shukla J 1991 A simplified biosphere model for climate studies; J. Climate 4 345-364 